\title{
Complete Spontaneous Regression of Lung Metastases after Resection of CIC-Rearranged Sarcoma: A Case Report
}

\author{
Gloria Marquina $^{a}$ Silvia Sanchez-Ramon $^{b}$ Ana Sarnago $^{b}$ Luis Ortega ${ }^{c}$ \\ Ana Bustos $^{d}$ Florentino Hernando $^{e}$ Juan Luis Cebrian ${ }^{f}$ Antonio Casado $^{a}$ \\ aDepartment of Medical Oncology, Hospital Universitario Clinico San Carlos, Madrid,

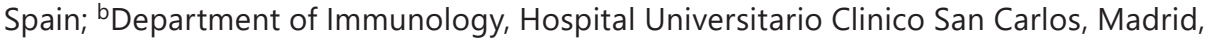 \\ Spain; 'Department of Pathology, Hospital Universitario Clinico San Carlos, Madrid, Spain; \\ ${ }^{\mathrm{d}}$ Department of Radiology, Hospital Universitario Clinico San Carlos, Madrid, Spain; \\ eDepartment of Thoracic Surgery, Hospital Universitario Clinico San Carlos, Madrid, Spain; \\ fDepartment of Orthopedic Surgery, Hospital Universitario Clinico San Carlos, Madrid, Spain
}

\author{
Keywords \\ ClC-Rearranged sarcoma $\cdot$ Spontaneous $\cdot$ Regression $\cdot$ Lung metastases
}

\begin{abstract}
The vast majority of patients with soft tissue sarcomas (STS) of the trunk and bilateral lung metastases at diagnosis are considered incurable. These tumors have poor prognosis as only a palliative therapeutic approach can be offered to patients. We report on an extremely rare case in which bilateral lung metastases disappeared spontaneously following surgical resection of the primary $\mathrm{ClC}$-rearranged sarcoma with no addition of chemotherapy or any other systemic therapy. A 53-year-old female presented with a rapidly swelling mass on her back. A magnetic resonance imaging scan of the chest revealed a large soft tissue mass on the posterior chest wall and bilateral lung metastases. Soon after stereotactic core-needle biopsy confirmation of round-cell sarcoma, the patient underwent surgery of the primary tumor as it started to be increasingly symptomatic. The resected specimen was pathologically diagnosed a poorly differentiated grade 3 sarcoma. Approximately 1 month later, a new CT scan revealed that the lung metastases were smaller and some of them had completely disappeared. Shortly afterward, the patient started adjuvant external beam radiotherapy of the tumor bed for 14 months. During the last follow-up visit, the patient confirmed no evidence of disease for 35 months postoperatively. In parallel, a histological study of pulmonary nodules, molecular analyses of the tumor, and a comprehensive study of the patient's immunophenotype were performed to gain some additional insights in the potential causes of this rare phenomenon.


Marquina et al.: Spontaneous Regression of Lung Metastases

\section{Introduction}

Soft tissue sarcomas (STS) are a group of rare, heterogeneous mesenchymal cancers that include around 50 different histological types of cancers arising from extraskeletal soft tissues. STS are rare tumors that represent approximately $1 \%$ of all adult tumors. An en bloc resection continues to be the cornerstone of management of early disease and the only curative option, whereas palliative systemic chemotherapy is the optimal treatment of advanced or unresectable STS. In general, spontaneous regression of any malignancy is infrequent; however, in STS such occurrence is extremely rare. Spontaneous regression of cancer is defined as the partial or complete disappearance of metastatic tumor in the absence of medical treatment or in the presence of treatment considered to be inadequate to produce a significant influence on tumor regression. Although several mechanisms have been proposed to explain the spontaneous regression of cancer, comprising complete surgical removal, fever and acute infection, allergic reaction, angiogenesis inhibition, enhanced apoptosis and epigenetic mechanisms, the underlying mechanisms of this phenomenon still remain uncertain. Among the various possibilities, enhancement of the immune system has been suggested to play an important role in both the progression and regression of cancers. Both experimental and clinical data support the involvement of the immune system in sarcoma tumorigenesis since immunosuppressed individuals present with a higher risk.

Herein, we report the case of a 53-year-old patient with CIC-rearranged sarcoma of the chest who achieved a spontaneous regression of bilateral lung metastases following excision of the primary tumor. We hypothesize that the lung metastases disappeared due to immunoreactivity induced by removal of the primary tumor that allowed the host immune system to control residual disease. During the patient's hospital course, informed consent was obtained from the patient for the presentation of her case along with the associated medical imaging.

\section{Clinical Presentation}

In July 2017, a 53-year-old female with no relevant medical history presented with the appearance of a rapidly growing mass on her back (Fig. 1, left panel). A magnetic resonance imaging (MRI) scan of the chest performed on August 1, 2017, revealed a large soft tissue mass on the posterior chest wall. The mass presented T1 hyperintensity and T2 hypointensity, thin linear fibrous hypointense septa within the tumor, with marked heterogeneous peripheral enhancement with an area of central necrosis, and hyperintensive infiltrations of the trapezoid muscle. The MRI also revealed bilateral lung nodules suggestive of lung metastases. Shortly afterward, a stereotactic core biopsy of the tumor mass revealed a round-cell sarcoma with a high mitotic rate and necrosis (Fig. 1, right panel). The immunohistochemistry (IHC) study showed intense and diffuse expression of BCL2, CD99, and nestin, and focal expression of CD56 ( $<10 \%$ cells). In contrast, no expression of CD45, Tdt, CKAE1-AE3, EMA, CD34, CD31, D240, S100, neurofilaments, actin, myogenin, MyoD1, myeloperoxidase, or CD15 were observed, nor were EWSR1 or SYT translocations detected. A whole-body positron emission tomography-computed tomography (PET-CT) scan performed on August 22, 2017, confirmed the presence of a large mass in the right upper chest wall with anteroposterior, transverse, and craniocaudal planes of $9.6 \times 13.7 \times 12.8 \mathrm{~cm}$ in size, respectively, and with an ${ }^{18} \mathrm{~F}$-fluorodeoxyglucose $\left({ }^{18} \mathrm{~F}\right.$-FDG) standardized uptake value (SUV) of 12.2 . In addition, multiple bilateral lung metastases were also observed (Fig. 2A-C), with the largest of them being $2.7 \mathrm{~cm}$ in greatest dimension and with an ${ }^{18} \mathrm{~F}$-FDG SUV of 6.8 located in the left lower lobe. Mediastinal paratracheal and axillary lymphadenopathies up to $1 \mathrm{~cm}$ in size and with an ${ }^{18}$ F-FDG SUV of 4.8 were also detected.

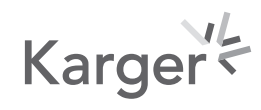




\section{Case Reports in Oncology}

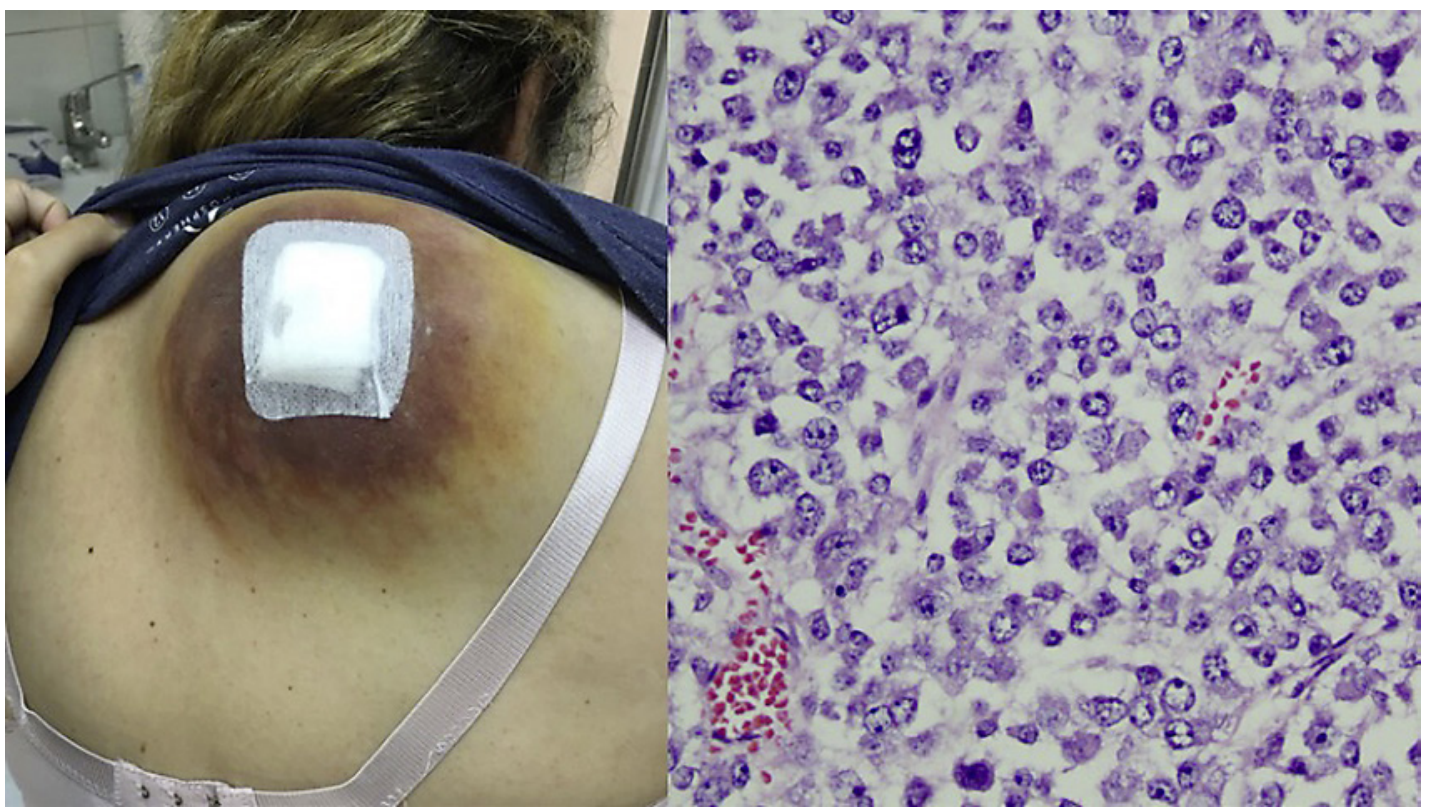

Fig. 1. Left panel: large mass on the posterior chest wall (picture taken on August 25, 2017). Right panel: anatomopathological correlation of the mass. HE stain preparation showed diffuse and neoplastic growth of small round cells with a scanty clear cytoplasm and nuclei containing fine chromatin.

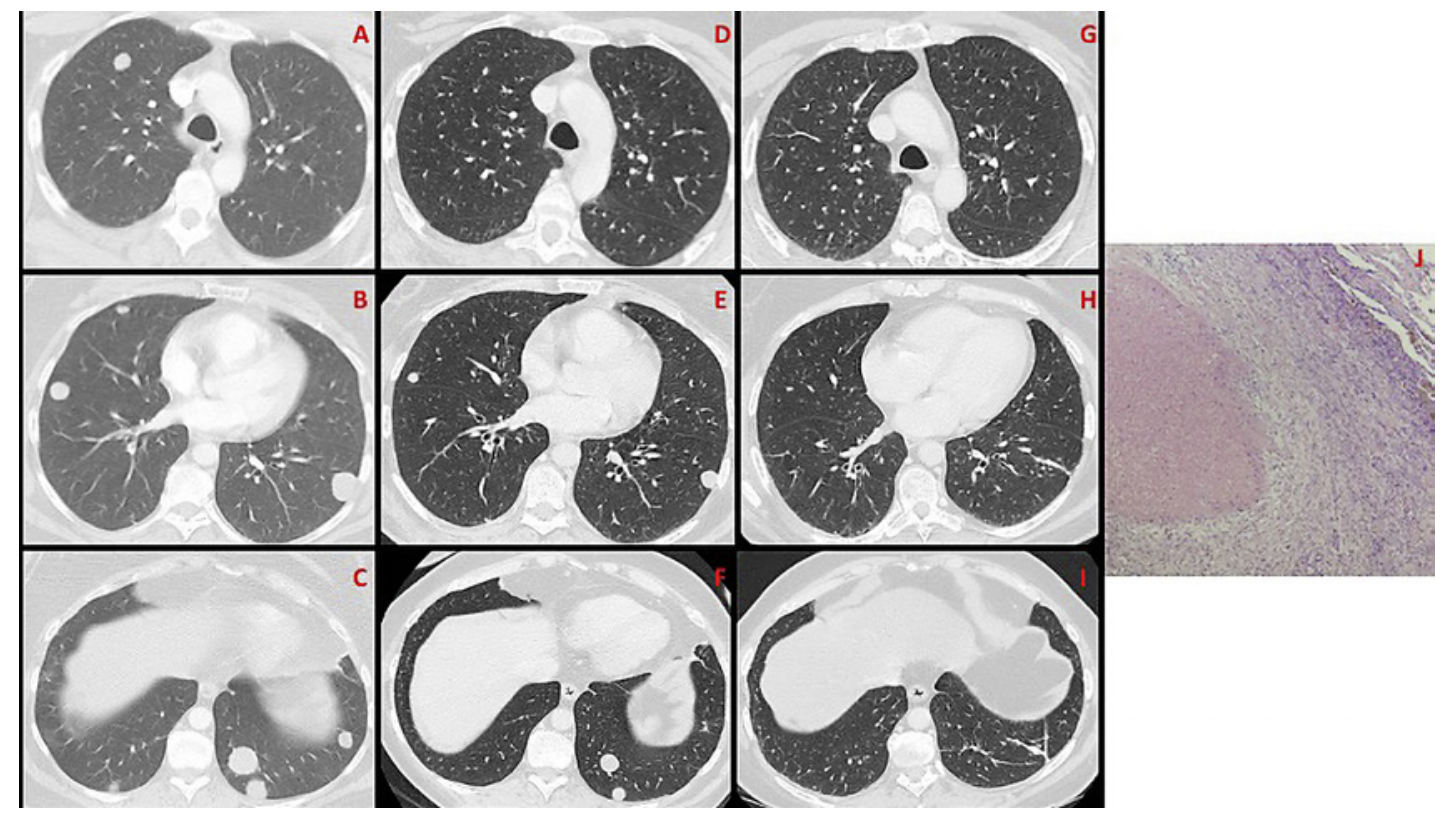

Fig. 2. A-C Images of the PET-CT scan performed on August 22, 2017, showing bilateral lung metastases. D-F CT scans performed on October 10, 2017, showing smaller lung metastases following primary tumor surgery. G-I CT scans performed in September 2019 showing the complete disappearance of lung metastases; surgical changes on the left lower lobe (left pulmonary node sampling surgery) are displayed in $\mathbf{I}$. J Anatomopathological correlation of one of the lung metastases. HE preparation showing a central area of necrotic cells surrounded by fibrous tissue with histiocytes and inflammatory cells. 
As the patient was increasingly symptomatic (i.e., in pain and discomfort) due to rapid growth of the sarcoma on her back, with the resulting high risk of local complications, the multidisciplinary sarcoma board agreed on resection of the primary tumor as the initial therapeutic approach. On September 5, 2017, radical en bloc resection of the right prescapular mass, including fascia and the underlying muscle plane, was performed. The resection margins were free of tumor cells, so the surgical procedure continued with immediate reconstruction using a musculocutaneous flap.

The histological report confirmed a poorly differentiated grade 3 round-cell sarcoma, whereas the IHC analysis revealed focal expression for CD56, nestin, CD99, and Factor VIII (focal), whereas no expression was detected for CD3, CD15, CD45, CD43, CD20, CD34, S100, HMB45, MART-1, SOX10, myeloperoxidase, D2-40, GFAP, caldesmon, actin, desmin, calponin, CD1a, CD21, CD23, CD68, BCL2, and MyoD1. In addition, the Ki-67 labeling index was high, with $50 \%$ positive cells in the late proliferation phase. Finally, the IHC analysis ruled out round-cell tumors as lymphoma, granulocytic sarcoma, or rhabdomyosarcoma, while through the use of fluorescence in situ hybridization probes we could rule out poorly differentiated sarcoma and Ewing sarcoma. So, in the absence of molecular analysis, a temporary diagnosis of round-cell sarcoma was considered.

Following surgery, a new CT scan of the chest, abdomen, and pelvis was performed on October 10, 2017. Surprisingly, pulmonary metastases were smaller than in previous radiographic studies and some of them had completely disappeared (Fig. 2D-F). Subsequently, we carried out a wedge resection of all four accessible nodules located in the left lower lung lobe (two in the basal pyramid, one in the sixth segment, and one in the lateral seventh segment). These lesions appeared even smaller in intraoperative palpation as compared to the last CT scan taken on October 10,2017. Histological analysis of the nodules found a core of necrotic material with ghost round cells, similar to the ones in the primary tumor, surrounded by histiocytes and fibrosis with no viable cells. The IHC study revealed focal positivity for CD99 in the necrotic cells. The case was brought to the multidisciplinary tumor board to discuss in depth the occurrence of unexpected regression of lung metastases after surgical resection of the primary tumor, both within the team and with the patient. The patient agreed to undergo recommended follow-up on a watch-and-wait strategy. A new CT scan of the chest performed in December 2017 showed a further dramatic shrinking in the vast majority of the remaining bilateral pulmonary metastases.

After these impressive findings and based on the diagnosis of highly malignant sarcoma, as recommended by the team, the patient was referred for adjuvant external beam radiotherapy of the tumor bed. Between February 14 and April 13, 2018, 66 Gy of adjuvant radiotherapy in 33 fractions were administered on the surgical bed and margins, including the surgical scar and skin. On the other hand, the patient has not received chemotherapy to date. Continuous patient follow-up showed the complete disappearance of lung metastasis, as confirmed by regular CT scans, with no evidence of relapse to date (Fig. 2G-J). The last followup was in June 2020, with no evidence of disease for 35 months postoperatively. Over the treatment period, the patient did not take any herbal remedies or alternative medicines and did not suffer from any infection that could possibly explain the disappearance of bilateral lung metastases after surgical removal of the primary lesion.

\section{Immunophenotypic and Genomic Profile of the Patient and Immune Status of the Tumor}

In an attempt to elucidate the putative role of the patient's immunity in the disappearance of bilateral lung metastases, in September 2018, when small bilateral lung metastases were still evident on the CT scan, peripheral blood mononuclear cells were extracted from $2 \mathrm{~mL}$ of peripheral blood from ethylenediaminetetraacetic acid blood tubes. With the aim to immunophenotype the patient, first we used multiparametric flow cytometry to elucidate

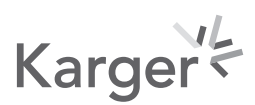


percentages of the main lymphocyte populations. The immunological assessment evidenced an expansion of the $\mathrm{CD}^{-} \mathrm{CD} 16^{+} \mathrm{CD} 56^{+}$natural killer (NK) cell subset $(27 \%$ of total lymphocytes; normal range 7.9-22.3\%) and a normal distribution of $\mathrm{CD}^{+} \mathrm{T}\left(57 \%\right.$; with $37 \% \mathrm{CD}^{+}$ and $20 \% \mathrm{CD}^{+} \mathrm{T}$ lymphocytes) and $\mathrm{CD} 19^{+} \mathrm{B}$ lymphocytes (16\%). The T-cell lineage showed a remarkable expansion of $\mathrm{CD}^{+} \mathrm{CCR}^{-} \mathrm{CD} 45 \mathrm{RA}^{-}$effector memory $\mathrm{T}$ lymphocytes (TEM) to $77 \%$ of total $\mathrm{CD}^{+}$cells (normal range 11.8-26.5\%). Proportions of $\mathrm{CD}^{+} \mathrm{T}$ lymphocyte subsets were normally distributed. The next comparative study was performed 6 months later (March 2019), when the patient already had no evidence of disease. NK cells were further expanded to $39 \%$ of total lymphocytes. Interestingly, CD4+ TEM cells were still high but decreased to $57 \%$, while $\mathrm{CD} 4^{+} \mathrm{CCR} 7^{+} \mathrm{CD} 45 \mathrm{RA} A^{-}$central memory $\mathrm{T}$ lymphocytes (TCM) increased from 17 to $29 \%$ (normal range 38.1-51.3\%). Comparable with the first evaluation, the $\mathrm{CD}^{+} \mathrm{T}$ lymphocyte distribution showed no remarkable changes. An additional and more detailed study of the NK population performed in May 2019 showed a clear predominance of cytotoxic NK cells $\left(91 \%\right.$ of $C D 16^{+}$CD $56^{\text {dim }}$ vs. $5 \%$ of CD56 $\left.6^{\text {bright }}\right)$. Within this subset, memorylike NK cells (CD16 ${ }^{+}$CD56 ${ }^{\text {dim }}$ CD57 ${ }^{\text {high }}$ NKG2 $C^{+}$) only accounted for $0.4 \%$.

In May 2019, a comprehensive study of PD-L1 expression in the primary tumor and metastases was carried out at the pathology department of our institution. Detection of the PD-L1 protein in formalin-fixed paraffin-embedded tissue was performed using the Dako EnVision FLEX detection system with monoclonal mouse PD-L1 Clone 22C3 pharmDx qualitative immunohistochemical kit (Agilent Technologies, Carpinteria, CA, USA) and the semiautomatic Dako Autostainer Link 48 platform. The analysis evidenced the PDL-1 expression of $<1 \%$ in the primary tumor and could not be assessed in the sample of lung metastases due to complete necrosis of the lesions. Moreover, the PD-L1 protein proportion was determined using the tumor proportion score, which, as in non-small-cell lung cancers, expressed the percentage of viable tumor cells showing partial or complete membrane staining at any intensity.

Additionally, CD 4 and CD8 lymphocyte counts in samples from the tumor and metastases were also performed using anti-CD4 and anti-CD8 monoclonal antibody kits (Agilent) with an EnVision FLEX visualization system on the Omnyx system. The lymphocyte population revealed a discrete quantity of T lymphocytes (CD3), with predominance of CD8 (>95\%), and very few CD4 in the sample of lung metastases.

Finally, In January 2019 the comprehensive genomic profiling FoundationOne ${ }^{\circledR}$ Heme test (Roche) was used to analyze genomic changes in the primary tumor. The test of the primary tumor revealed a CIC-DUX4 fusion, stable microsatellite status of the tumor, and low tumor mutational burden and 2 mutations/Mb. It is noteworthy that our finding of a CIC-DUX4 fusion allowed us to achieve a correct diagnosis considering that the last WHO classification of soft tissue tumors recognizes CIC-rearranged sarcomas as a new entity within undifferentiated small-round-cell sarcomas of bone and soft tissue [1]. Lastly, the test could not be applied to the lung nodules due to the absence of viable cells.

\section{Discussion}

The reported case illustrates the so-called phenomenon of spontaneous regression of sarcoma, previously described in the scientific literature since 1946 [2] and whose mechanisms still remain unclear. Since then, only 10 previous cases [2-11] have been described in the English-language literature (Table 1). Unfortunately, in previously published cases no molecular or immunological analyses have been performed to further elucidate the intrinsic causes of regression of primary sarcoma and/or metastases. To the best of our knowledge, this is the first report of complete disappearance of sarcoma metastases after removal of the

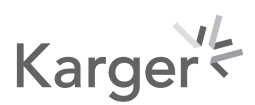


Table 1. Prior case reports (in chronological order) on sarcoma patients who had evidence of spontaneous regression of primary tumor and/or metastases

\begin{tabular}{|c|c|c|c|c|c|c|c|}
\hline \multirow{2}{*}{$\begin{array}{l}\text { First author, } \\
\text { publication } \\
\text { year }\end{array}$} & \multirow{2}{*}{$\begin{array}{l}\text { Patient age, } \\
\text { years/ } \\
\text { gender }\end{array}$} & \multirow{2}{*}{$\begin{array}{l}\text { Primary tumor }(\mathrm{PT}) / \\
\text { treatment }\end{array}$} & \multicolumn{3}{|l|}{ Metastases } & \multirow{2}{*}{$\begin{array}{l}\text { Follow-up } \\
\text { period }\end{array}$} & \multirow{2}{*}{$\begin{array}{l}\text { Metastases shrinkage after } \\
\text { surgery }\end{array}$} \\
\hline & & & onset/diagnosis & sites & $\begin{array}{l}\text { histological } \\
\text { specimen }\end{array}$ & & \\
\hline $\begin{array}{l}\text { Rosenman [2], } \\
1946\end{array}$ & $59 /$ male & $\begin{array}{l}\text { Right tibia chondrosarcoma. } \\
\text { Treated with radiotherapy }\end{array}$ & At diagnosis & Lung & Yes (biopsy) & 2 years & $\begin{array}{l}\text { Yes. Disappearance of left } \\
\text { lung nodules }\end{array}$ \\
\hline \multirow[t]{2}{*}{$\begin{array}{l}\text { Ogihara [3], } \\
1994\end{array}$} & 19/male & $\begin{array}{l}\text { Left femur osteosarcoma. } \\
\text { Treated with chemotherapy }\end{array}$ & $\begin{array}{l}5 \text { months after PT surgery } \\
\text { and chemotherapy }\end{array}$ & Lung & No & 26 years & $\begin{array}{l}\text { No. Still persistent } \\
\text { metastasis }\end{array}$ \\
\hline & $11 /$ male & $\begin{array}{l}\text { Right femur osteosarcoma. } \\
\text { Treated with chemotherapy }\end{array}$ & $\begin{array}{l}12 \text { months after PT surgery } \\
\text { and chemotherapy }\end{array}$ & Lung & $\begin{array}{l}\text { Yes (surgical } \\
\text { removal of } 6 \text { lung } \\
\text { nodules) }\end{array}$ & 13 years & $\begin{array}{l}\text { No. Still persistent } \\
\text { metastasis }\end{array}$ \\
\hline $\begin{array}{l}\text { Sabaté [4], } \\
1998\end{array}$ & 69/female & $\begin{array}{l}\text { Extraskeletal osteosarcoma } \\
\text { of the abdominal wall }\end{array}$ & $\begin{array}{l}14 \text { months after PT surgery, } \\
\text { radiation and chemotherapy }\end{array}$ & Lung & No & 2 years & $\begin{array}{l}\text { No. PT was removed months } \\
\text { before the metastatic onset }\end{array}$ \\
\hline $\begin{array}{l}\text { Ota }[5] \\
2002\end{array}$ & 58/female & $\begin{array}{l}\text { Endometrial stromal } \\
\text { sarcoma }\end{array}$ & 8 years after PT surgery & Lung & $\begin{array}{l}\text { Yes (left lower lobe } \\
\text { nodule resection) }\end{array}$ & 6 years & $\begin{array}{l}\text { No. PT was removed months } \\
\text { before the metastatic onset }\end{array}$ \\
\hline $\begin{array}{l}\text { Kim [7], } \\
2008\end{array}$ & $72 /$ female & $\begin{array}{l}\text { Left breast epithelioid } \\
\text { angiosarcoma }\end{array}$ & 1 year after PT surgery & Lung & No & 6 months & $\begin{array}{l}\text { No. PT was removed months } \\
\text { before the metastatic onset }\end{array}$ \\
\hline $\begin{array}{l}\text { Bacci [6], } \\
2008\end{array}$ & $19 /$ male & $\begin{array}{l}\text { Grade } 4 \text { osteoblastic } \\
\text { osteosarcoma of the right } \\
\text { distal femur }\end{array}$ & $\begin{array}{l}\text { Second lung relapse ( } 4 \text { years } \\
\text { after PT surgery) }\end{array}$ & Lung & $\begin{array}{l}\text { Yes (fine-needle } \\
\text { biopsy) }\end{array}$ & 8 years & $\begin{array}{l}\text { No. PT was removed months } \\
\text { before the metastatic onset. } \\
\text { Two prior relapses (lung } \\
\text { and left arm) were } \\
\text { surgically removed }\end{array}$ \\
\hline $\begin{array}{l}\text { BaniHani [8], } \\
2009\end{array}$ & $38 /$ male & $\begin{array}{l}\text { Alveolar soft part sarcoma of } \\
\text { the trunk }\end{array}$ & At diagnosis & $\begin{array}{l}\text { Lung, } \\
\text { stomach }\end{array}$ & $\begin{array}{l}\text { Yes (stomach } \\
\text { metastases) }\end{array}$ & 5 months $^{1}$ & $\begin{array}{l}\text { Yes. PT and lung metastases } \\
\text { experienced tumor } \\
\text { shrinkage }\end{array}$ \\
\hline $\begin{array}{l}\text { Sakamoto [9], } \\
2014\end{array}$ & $85 /$ female & $\begin{array}{l}\text { Myxofibrosarcoma of the left } \\
\text { scapula }\end{array}$ & No metastases & NA & NA & 2 years & $\begin{array}{l}\text { Shrinkage of the PT after } \\
\text { pneumonia infection. The } \\
\text { PT remained smaller for } 12 \\
\text { months and increased again }\end{array}$ \\
\hline $\begin{array}{l}\text { Sugihara [10], } \\
2015\end{array}$ & $59 /$ male & $\begin{array}{l}\text { Grade II chondrosarcoma of } \\
\text { the left proximal femur }\end{array}$ & 1 year after PT surgery & Lung & No & Unknown & No \\
\hline $\begin{array}{l}\text { Mizuno [11], } \\
2019\end{array}$ & $62 /$ male & $\begin{array}{l}\text { Myxofibrosarcoma of the } \\
\text { right tight }\end{array}$ & No metastases & NA & NA & 1 year & $\begin{array}{l}\text { Shrinkage of the PT after } \\
\text { open biopsy. No metastasis }\end{array}$ \\
\hline $\begin{array}{l}\text { Current case, } \\
2020\end{array}$ & 59/female & $\begin{array}{l}\text { Grade } 3 \text { CIC-rearranged } \\
\text { round-cell sarcoma of the } \\
\text { chest }\end{array}$ & At diagnosis & Lung & Yes & $\begin{array}{l}\text { Approx. } 3 \\
\text { years }\end{array}$ & Yes \\
\hline
\end{tabular}

NA, not available; PT, primary tumor. ${ }^{1}$ Patient died due to brain progressive disease.

primary CIC-rearranged sarcoma, which also includes a comprehensive study of the patient's immunity and a molecular analysis of the tumor. An all-inclusive understanding of this phenomenon is crucially important as it can provide useful insights for researchers and clinicians to delineate future research hypotheses and treatments. CIC-rearranged sarcomas have been relatively recently described as an independent molecular and clinical subset of smallround-cell tumors distinct from Ewing sarcoma. Although they share partial morphologic overlap with Ewing sarcoma and variable CD99 expression, emerging molecular data suggest that CIC-DUX4 tumors have a distinct pathogenesis [1].

The concept of tumor immunosurveillance, as a process through which immune systems continuously exert immune surveillance and eliminate self-cells that have become transformed through either spontaneous or chemically induced genetic alterations, was supported by numerous reports over the past years [12], but was also questioned by others [13]. In contrast, immune control of virally induced tumors has never been a controversial issue. Our 
results are in line with other studies in cancer patients where accumulation of CD4 and/or CD8 cells within the memory/effector phenotype correlated well with better prognosis and survival. Those findings support the existence of immunosurveillance in sarcoma patients, in which the host-protective response outweighs tumor-promoting roles of the immune system [12]. It is well known that once a tumor mass has developed, generation of TCM cells is largely impaired, suggesting that tumor growth compromises differentiation of this compartment. Moreover, this phenotype is rapidly lost upon sustained antigenic stimulation, as occurs in large tumors and metastases, being concomitant with terminal differentiation to TEM cells and short-lived effector cells [14]. Therefore, we can only speculate that reduction of the magnitude of antigen presentation and inflammation, as occurs after tumor mass resection, may promote the expansion of TCM cells and elimination of the tumor cells. Additional studies on cellular and molecular mechanisms are warranted to confirm this hypothesis, and to try to elucidate the cause of expansion of cytNK cells, as well as its possible relationship with regression of the patient's metastases. Furthermore, NK cells are promising candidates for cancer immunotherapy as they exert nonspecific anti-tumor activity upon detection of a complex array of tumor ligands. Patients with a high level of NK infiltration were found to have a higher survival rate and a better prognosis than those with a low level of NK infiltration. While it is true that an inverse relationship is observed between the number of circulating and/or infiltrating NK cells in the tumor and the presence of metastases in different types of tumors, the mechanisms through which they exert their effect have not been thoroughly explored in the context of sarcoma immunotherapy [15]. Finally, a comprehensive analysis of the tumor microenvironment may also help us to better understand the mechanism of action of drugs that act on both cancer cells and the tumor microenvironment.

The case reported here is unique considering the fact that we obtained histological specimens of both the primary tumor and metastases, which were analyzed as much as the paraffin samples permitted. Additionally, the patient has undergone several regular blood analyses to try to ascertain her immune profile and generate a hypothesis that the immune system and particular conditions of the tumor microenvironment may explain the spontaneous regression of lung metastases. Finally, there was no intercurrent maneuver that could possibly potentiate the disappearance of the bilateral lung metastases (e.g., infection, intake of herbs, use of other alternative methods). Thus, the results of this case suggest that the mechanism by which spontaneous tumor regression occurred was immune-mediated tumor rejection. However, to verify this hypothesis, the presence of T cells and NK cells specific against the tumor has to be demonstrated. Apart from the fact that such analyses require complex highperformance techniques not available at our hospital (e.g., peptidomic assays, ELISPOT), the lack of fresh tumor tissue and blood samples, from diagnosis and throughout the follow-up, hampered us in performing additional studies of the immune profile of the patient.

In conclusion, to our knowledge this is the first report documenting the spontaneous regression of bilateral lung metastases following excision of the primary CIC-rearranged sarcoma of the chest. Further studies of the mechanism of immune activation are warranted, particularly regarding more precise tumor characterization, targeted immunomodulation of the individual tumor microenvironment, and targeting of sarcoma-specific molecules, as they may lead to new treatment strategies for the treatment of STS.

\section{Acknowledgments}

The authors acknowledge Luis Garcia Palacios, Spain's Roche-Foundation Medicine medical leader for scientific support.

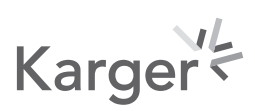




\section{Case Reports in Oncology}

\begin{tabular}{l|l}
\hline Case Rep Oncol 2021;14:152-159 \\
\hline DOI: 10.1159/000512276 & $\begin{array}{l}\text { @ 2021 The Author(s). Published by S. Karger AG, Basel } \\
\text { www.karger.com/cro }\end{array}$ \\
\hline
\end{tabular}

Marquina et al.: Spontaneous Regression of Lung Metastases

\section{Statement of Ethics}

Written informed consent was obtained from the patient for the presentation of her case along with the associated medical imaging.

\section{Conflict of Interest Statement}

The authors have no conflicts of interest to declare.

\section{Funding Sources}

The authors received no financial support for the research and authorship of this article. Publication was supported by a grant from Roche-Foundation Medicine Spain.

\section{Author Contributions}

G.M., L.O., A.B., F.H., J.L.C., and A.C. participated directly in the care and diagnosis of the patient as members of the multidisciplinary sarcoma team, whereas S.S.-R. and A.S. performed immunological studies. All authors performed the literature review and drafted, reviewed, and approved the final version of the case report.

\section{References}

1 Fletcher C, Bridge J, Antonescu C, Mertens F. WHO classification of tumours: soft tissue and bone tumours. 5thed, vol 3. Lyon: International Agency for Research on Cancer; 2020.

2 Rosenman RH. Spontaneous regression of metastatic sarcoma; report of case. Am J Clin Pathol. 1946 Apr;16: 281-9.

3 Ogihara Y, Takeda K, Yanagawa T, Hirasawa Y. Spontaneous regression of lung metastases from osteosarcoma. Cancer. 1994 Nov 15;74(10):2798-803.

4 Sabaté JM, Llauger J, Torrubia S, Amores S, Franquet T. Osteosarcoma of the abdominal wall with spontaneous regression of lung metastases. AJR Am J Roentgenol. 1998 Sep;171(3):691-2.

5 Ota S, Shinagawa K, Ueoka H, Tada S, Tabata M, Hamazaki S, et al. Spontaneous regression of metastatic endometrial stromal sarcoma. Jpn J Clin Oncol. 2002 Feb;32(2):71-4.

6 Bacci G, Palmerini E, Staals EL, Ferrari S, Battaglia M, Longhi A, et al. Spontaneous regression of lung metastasis from osteosarcoma: a case report. J Pediatr Hematol Oncol. 2008 Jan;30(1):90-2.

7 Kim SW, Wylie J. Spontaneous regression of pulmonary metastases from breast angiosarcoma. Sarcoma. 2008; 2008:940656.

8 BaniHani MN, Al Manasra AR. Spontaneous regression in alveolar soft part sarcoma: case report and literature review. World J Surg Oncol. 2009 Jun 10;7:53.

9 Sakamoto A, Shiba E, Hisaoka M. Short-term spontaneous regression of myxofibrosarcoma in the scapular region. Skeletal Radiol. 2014 Oct; 43(10):1487-90.

10 Sugihara S. Spontaneous regression of lung metastatic lesions from chondrosarcoma. J Cancer Sci Ther. 2015; $7(10)$. th

11 Mizuno T, Susa M, Horiuchi K, Shimazaki H, Nakanishi K, Chiba K. Spontaneous regression of myxofibrosarcoma of the thigh after open biopsy. Case Rep Oncol. 2019 May-Aug;12(2):364-9.

12 Dunn GP, Bruce AT, Ikeda H, Old LJ, Schreiber RD. Cancer immunoediting: from immunosurveillance to tumor escape. Nat Immunol. 2002 Nov;3(11):991-8.

13 Stutman 0. Tumor development after 3-methylcholanthrene in immunologically deficient athymic-nude mice. Science. 1974 Feb 8;183(4124):534-6.

14 Wherry EJ. T cell exhaustion. Nat Immunol. 2011 Jun;12(6):492-9.

15 Sayitoglu EC, Georgoudaki AM, Chrobok M, Ozkazanc D, Josey BJ, Arif M, et al. Boosting natural killer cellmediated targeting of sarcoma through DNAM-1 and NKG2D. Front Immunol. 2020;11:40. 